Article

\title{
Operability and Technical Implementation Issues Related to Heat Integration Measures-Interview Study at an Oil Refinery in Sweden
}

\author{
Sofie Marton ${ }^{1, *}$, Elin Svensson ${ }^{2}\left(\mathbb{D}\right.$ and Simon Harvey ${ }^{1}(\mathbb{C}$ \\ 1 Division of Energy Technology, Department of Space, Earth and Environment, Chalmers University of \\ Technology, 41296 Gothenburg, Sweden; simon.harvey@chalmers.se \\ 2 CIT Industriell Energi AB, 41258 Gothenburg, Sweden; elin.svensson@chalmersindustriteknik.se \\ * Correspondence: sofie.marton@chalmers.se
}

Received: 6 May 2020; Accepted: 3 July 2020; Published: 5 July 2020

\begin{abstract}
In many energy-intensive industrial process plants, significant improvements in energy efficiency can be achieved through increased heat recovery. However, retrofitting plants for heat integration purposes can affect process operability. The aim of this paper is to present a comprehensive overview of such issues by systematically relating different types of heat recovery retrofit measures to a range of technical barriers associated with process operability and practical implementation of the measures. The paper presents a new approach for this kind of study, which can be applied in the early-stage screening of heat integration retrofit measures. This approach accounts for the importance of a number of selected operability factors and their relative significance. The work was conducted in the form of a case study at a large oil refinery. Several conceptual heat exchanger network retrofit design proposals were prepared and discussed during semi-structured interviews with technical staff at the refinery. The results show that many operability and practical implementation factors, such as spatial limitations, pressure drops and non-energy benefits, influence the opportunities for implementation of different types of heat exchanger network retrofit measures. The results indicate that it is valuable to consider these factors at an early stage when designing candidate heat exchanger network retrofit measures. The interview-based approach developed in this work can be applied to other case studies for further confirmation of the results.
\end{abstract}

Keywords: heat integration; operability; retrofit; oil refinery; interviews

\section{Introduction}

There are currently many driving forces to incentivize increasing energy efficiency in industry. For example, the European Union's Energy Efficiency Directive [1] has resulted in national laws requiring large companies to perform energy audits to identify measures for energy efficiency. Environmental legislation, various incentives, and policy support programs for energy efficiency, as well as economic and environmental concerns from customers and business partners, all motivate a stronger focus on energy efficiency in process industry companies.

However, technical, economical, and organizational barriers often hinder implementation of energy efficiency measures. Fleiter et al. [2] stress the importance of distinguishing between different types of energy efficiency measures when discussing barriers for energy efficiency. For example, the risk of production disruption is one of the most important barriers when the energy efficiency measures can affect the core process. Dieperink et al. [3] discussed difficulties associated with implementing energy efficiency measures that affect the core process for selected industrial sites in the Netherlands. Rhodin et al. [4] presented an example from the Swedish foundry industry where technical risks such 
as production disruptions was the second largest barrier for implement energy efficiency measures. Thollander and Ottosson [5] discussed an example from the Swedish pulp and paper industry in which technical difficulties were also ranked as a large obstacle for implementing energy efficiency measures. Cagno and Trianni [6] also addressed the importance of considering barriers for specific energy efficiency measures, rather than assuming that barriers are the same for all types of measure. This implies that research is needed that addresses a variety of industrial sectors, as well as different types of energy efficiency measures, in order to thoroughly evaluate and investigate which factors affect the implementation potential. Much research has been conducted concerning drivers and barriers in small and medium-sized enterprises. Johansson and Thollander [7] discussed drivers and barriers and suggested recommendations for in-house energy management procedures for several industrial sectors in Sweden, including both small and medium-sized enterprises and energy-intensive industry. Cagno et al. [8] presented a framework for assessing non-energy benefits and non-energy losses that is targeted at industrial decision-makers and covers both technical and management perspectives. However, only a few studies have focused on large energy-intensive industrial plants, such as the Swedish pulp and paper industry [5], the Swedish iron and steel industry [9], and the German steel industry [10], and the lack of studies from the petrochemical process industry is noteworthy.

Changes to an industrial process can have major effects on process operability. It is therefore imperative that operational issues are considered when planning such changes. Process operability includes different operational aspects such as flexibility, controllability, reliability, availability, and start-up and shutdown of the process [11]. For example, if a process is not flexible it cannot adapt to different operating conditions, such as varying feedstock, change of product specifications and/or product mix, and varying ambient conditions. Equipment reliability/availability issues can cause expected and unexpected operational disruptions and controllability problems can lead to major safety issues and production disruptions. Therefore, it is important to investigate how energy efficiency can affect operability. Furthermore, energy efficiency measures can also improve operability, for example by reducing the load on a process capacity-limiting furnace, leading to valuable non-energy benefits for the process. Non-energy benefits refer to benefits other than the direct energy cost savings from the energy efficiency improvement, e.g., reduced carbon dioxide emissions, increased production, and better work environment [12].

Although there are several options to increase energy efficiency in industry, thermal energy is used in large quantities in chemical process plants and heat recovery is therefore one important option to improve energy efficiency in such plants. In previous research, many case studies have identified large techno-economic potentials for energy savings by heat integration in existing industrial plants. To evaluate feasibility of new processes and increased energy efficiency through increased heat recovery, a better estimation of the techno-economic potentials of process heat integration measures is necessary as well as a better understanding of the drivers and barriers affecting the implementation potential. Rebuilding an existing industrial plant to increase heat integration affects the process in several ways. In particular, the number of interdependencies between different parts of the process increases. In previous studies it has been repeatedly discussed that the risk for operability or control problems is strongly connected to the number of interdependencies and interconnections within a process. Subramanian and Georgakis [13] investigated plant-wide steady-state operability issues for an integrated process plant. Setiawan and Bao also discussed the connection between an integrated process and operability issues, both in a study considering interactions between process units [14] and in a study that investigates interaction effects connected to operability [15]. Such operability problems may lead to production disruptions, which must be avoided since they are extremely costly. This underlines the importance of considering operability of heat integration measures at an early stage when investigating retrofits of industrial energy systems.

Heat integration analysis can be based on mathematical programming or graphical insights (e.g., pinch analysis) (see e.g., [16]). A wide variety of case studies have shown a large potential for increased energy efficiency through retrofitting of heat exchanger networks (HENs) at different 
industrial process sites. There are many different methodologies to identify HEN retrofit designs that achieve high energy savings at low cost, each of which has their own benefits and drawbacks (see e.g., [17] for a review of HEN retrofit methodologies and applications). It is common that several HEN designs can be identified that achieve approximately the same energy saving at similar costs. However, such HEN designs can vary significantly regarding network complexity, placement of new heat exchangers, as well as utility heaters and coolers for target temperature control, etc. It is thus clear that technical and operational factors need to be considered together with investment cost and fuel cost savings when investigating HEN retrofit options.

In the existing literature, there are many studies presenting methods for accounting for specific practical considerations and associated costs in HEN retrofit studies. For example, Becker and Maréchal [18] presented a method to consider heat exchange restrictions using mixed integer linear programming, and Cerda and Westerburg [19] presented a study of HEN synthesis with restricted stream matches. Polley and Kumana [20] suggested dividing larger networks into a number of smaller networks to deal with large heat integration projects. Practical considerations and associated costs are especially important when considering integration at large sites or even across company boundaries, which is the case, for example, for piping and pressure drops. To include plant-specific factors such as piping costs, pressure drop, and heat losses, Bütün et al. [21] proposed a mixed integer linear programming framework. Hiete et al. [22] also included piping costs when considering energy integration between industrial plants with different owners. Jegla and Freisleben [23] also considered pressure drops in their practical method for energy retrofit, but in addition they also considered available heat exchanger space. Reddy et al. [24] presented an optimization method for retrofits of cooling water systems including pressure drops, cooling tower operation, and piping costs. Hackl and Harvey [25] developed a methodology for identifying cost-effective retrofit measures in a chemical cluster adopting a total site perspective. Nemet et al. [26] developed methods for included piping costs, pressure drops, and temperature drops in total site analyses.

Other methods have also been proposed to account for certain specific operability considerations such as flexibility and controllability in network design. Escobar et al. [27] suggested a method to include flexibility and controllability consideration in HEN synthesis. Another method for including operability and observability in HEN design was recently proposed by Leitod et al. [28]. Andiappan and $\mathrm{Ng}$ [29] presented a methodology to consider energy systems operability, feasibility and debottlenecking opportunities connected to retrofit design. Abu Bakar et al. [30] suggested including operability in addition to investment and utility cost savings in the choice of $\Delta \mathrm{T}_{\min }$ for HEN design. Several authors have used mixed-integer programming for multi-period optimization to consider flexibility in process integration problems, for example, for integration of utility systems [31], flexible HEN design [32], and integration of biomass and bioenergy supply networks [33]. Bütün et al. [34] presented an approach for including multiple investment periods for a longer time horizon for energy integration.

Although many studies have focused on specific individual aspects of process operability, there is, to the best of our knowledge, no scientific literature that provides a comprehensive overview of the wide variety of process operability issues and that systematically investigates their impact on decision processes related to implementation of HEN retrofit measures. Furthermore, operability issues are traditionally not considered at the early conceptual design stage for techno-economic ranking of alternative heat integration measures. One common approach in HEN retrofit studies is to identify pinch rules violations in the existing HEN, and thereafter attempt to remove or reduce such violations starting with the largest violation. At this early design stage, it is unusual to consider costs other than heat exchanger and utility costs. Operability issues are usually not included until the pre-feasibility or feasibility study phases of the decision-making process for heat integration projects, see Figure 1 . However, since energy efficiency measures for increased heat integration are closely connected to the core process of industrial plants, technical aspects can be assumed to be important barriers for their implementation. By considering possible technical barriers and operability issues at an earlier stage of the screening process of energy efficiency options, it could be possible to avoid spending resources on 
detailed design and feasibility studies of projects that are highly unlikely to be implemented. This is crucial to enable a rapid and relevant screening process of energy efficiency measures and to be able to estimate accurate technical and economical potentials of heat integration. To enable more explicit consideration of operability issues earlier in the screening process, it is, however, important to know which operability factors are most important to consider in the techno-economic evaluation.



Figure 1. Decision-making process for process development projects.

The aim of this paper is to present a comprehensive overview of operability and technical implementation issues related to heat integration measures by mapping, discussing and clarifying how such measures relate to a comprehensive set of key operability factors. This approach differs from previous studies that have primarily investigated these issues individually. The work was conducted in the form of an interview study at a large oil refinery in Sweden, and as such suggests a new approach for inclusion of operability considerations at an early stage of screening of alternative heat integration options. The paper aims to present an in-depth discussion of the theoretical definitions of operability and the practical considerations of heat integration by investigating its relevance in a real industrial process plant. The case study contributes to expanding the knowledge base for operability and practical implementation issues related to heat integration retrofits.

\section{Definition and Categorization of Operability}

The following definitions were proposed in previous work by the authors, based on a review of the literature in the area of operability issues related to heat integration [10]. Operability is defined as

"... the ability to operate equipment, process units and total sites at different external conditions and operating conditions, without negatively affecting safety or product quality and quantity. This includes both steady-state and dynamic aspects of operation."

It was also proposed to distinguish between a number of operability aspects that can be sorted into the following sub-categories: flexibility, controllability, feasibility of start-up/shutdown transitions, reliability, availability, and other practical considerations. These sub-categories were based on the following considerations:

Flexibility:

"A flexible process has the ability to maintain feasible operation for different operating scenarios. For oil refining processes, flexibility includes, for example, being able to handle different crude recipes, product mixes and ambient conditions. Flexibility also includes the ability for the operation to handle long-term variations within the process, such as decreased reactivity in catalyst beds and decreased heat transfer due to fouling."

Controllability refers to

"... the ability to maintain a stable process, while handling disturbances and short-term variations to the process. According to our choice of definition, it also includes being able to maintain a stable process during transition from one operating scenario to another."

Feasibility of startup/shutdown transitions refers to 
"... the ability to start up or shut down the process in a controlled and safe manner. Due to the special characteristics of startup/shutdown transitions, this is important to consider separately, although it is essentially included in the afore-mentioned definition of controllability."

Reliability refers to

"... the ability to operate a process without unexpected equipment failure."

Whereas availability on the other hand refers to

"... the expected operating time for equipment during a time period that also includes planned maintenance."

Practical considerations are not per se strictly related to operability only but are nevertheless included in the analysis, given their importance related to implementation of HEN retrofit measures [16]. Examples of practical implementation issues include space for new equipment, time availability for retrofitting during major process maintenance shut-down periods and accessibility for erecting new equipment.

\section{Industrial Case Study Plant}

To thoroughly discuss operability of heat integration measures, a single plant was considered in the case study, which gave the opportunity to design and evaluate retrofit proposals based on real process data. Large industrial plants include many interconnected process units and extensive utility systems. A comprehensive data collection and analysis is thus essential to obtain the details necessary to identify candidate HEN retrofit measures and related operability aspects. In this work, a single process plant was investigated in detail, which provided the opportunity to design HEN retrofits (see Section 4.2) that include many of the aforementioned operability aspects and discuss the proposed retrofit measures in detail with refinery staff. This level of detail would not have been possible if several plants were included in the study.

The case study was conducted at one of the most modern and energy efficient complex oil refineries in Europe, with a crude oil capacity of 11.5 million tons per year and total $\mathrm{CO}_{2}$ emissions of 1.6 million tons in 2017 [35]. The main products are petrol, diesel, propane, propylene, butane, and bunker oil.

The heat demand of the refinery is satisfied mainly by direct fired process furnaces and by steam that is produced in steam boilers, flue-gas heat recovery boilers and process coolers. The process furnaces and steam boilers are fired by fuel gas that consists mainly of non-condensable gases from the refinery distillation columns. Liquefied Natural Gas (LNG) is used as make-up fuel when the non-condensable gas fuel stream is insufficient. An overview of the main material and energy flows is presented in Figure 2.

The refinery steam network consists of four main pressure headers, which are connected by let-down valves and turbines. The turbines are used in direct drive configuration to operate compressors and pumps, a number of which can be switched to electric motor drive. There is no electrical power generation on site. The refinery regularly has an excess of low-pressure steam. During $25 \%$ of the year, the excess of low-pressure steam is particularly high due to an excess of non-condensable gases from the refinery processes. Flaring is strictly regulated, and the refinery has no storage capacity for the non-condensable gases, thus excess gas is combusted in the steam boilers, leading to an excess of steam that is vented. 


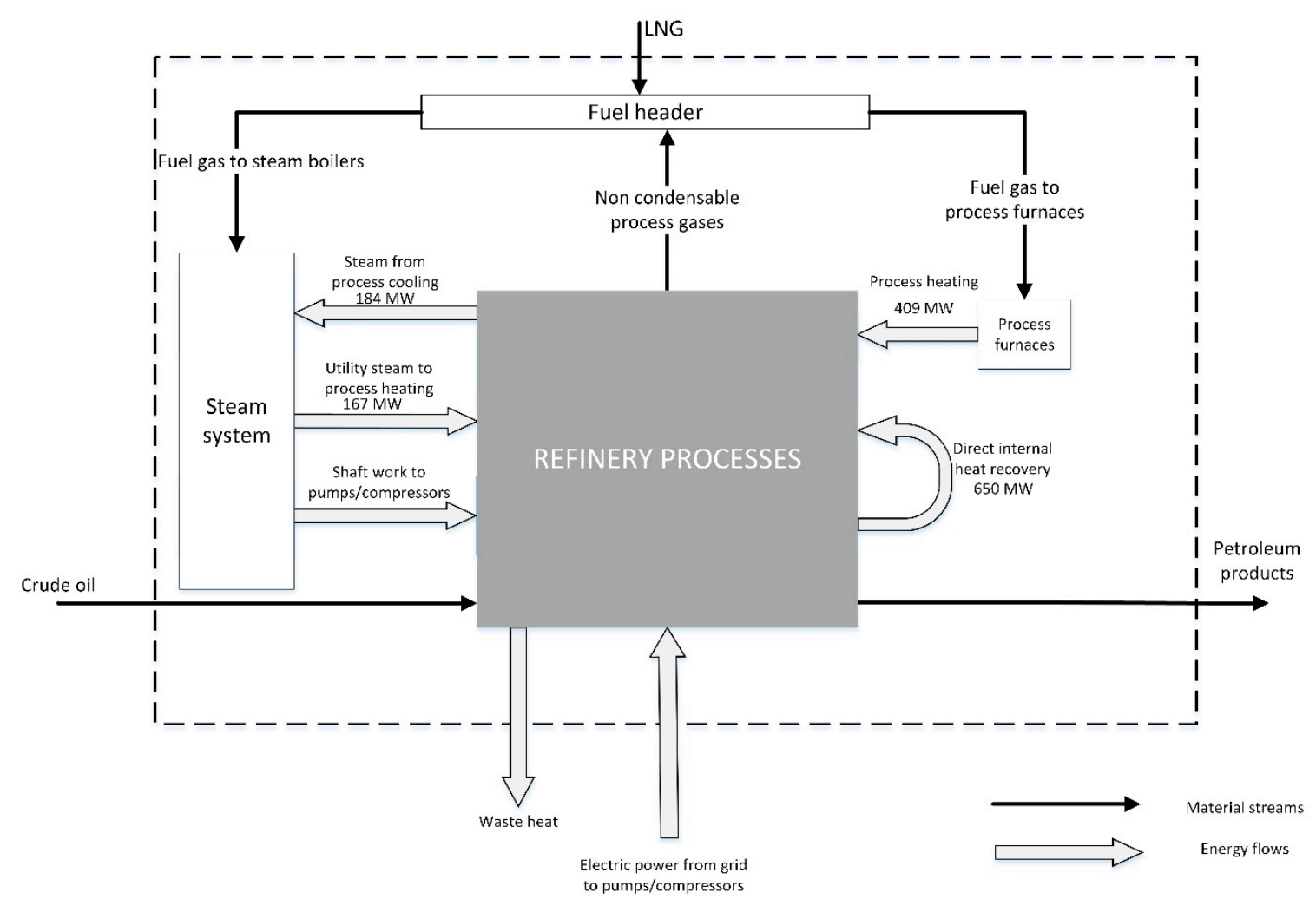

Figure 2. Major material and energy flows of the studied refinery. Data for shaft work from steam turbines and electricity to pumps/compressors was not collected at the same time as the process stream data. The refinery steam system is described in detail in reference [36].

In connection to earlier research projects, energy targeting [37] and retrofit studies [38] have been carried out for the case study refinery. In this work, stream temperature and heat load data were collected for the majority of the refinery heat exchangers. Process stream data was collected 23 April 2010 from production data control room screen shots and data logs. The date was chosen in collaboration with refinery engineers to represent stable full capacity operation. For these operating conditions, the process hot utility demand that was covered by process furnaces was determined to be 409 MW [37]. Minimum utility requirements were determined for the different process units using pinch analysis. Details about the results of this energy targeting are presented in Section 4.2.

\section{Methodology}

In this section, the framework for the interview study is described as well as the methods used for the interviews and HEN retrofit design.

Although scientific literature is scarce on the subject of operability related to heat integration measures, many experienced engineers and operators in industry possess a deep knowledge and understanding of their processes and the way they operate under various conditions. To be able to tap into this extensive knowledge base, a case study approach based on interviews was adopted. As discussed by Sovacool in references $[39,40]$, this approach provides a broader and more detailed perspective of process operation compared to simulation using a computer model which includes only known parameters and variables. Since limited research is available on the operability aspects that are most important to consider in a HEN retrofit study, a mapping is needed which can thereafter provide guidance for future HEN retrofit evaluations.

An overview of the methodology used for the interview study is shown in Figure 3. As the figure shows, HEN retrofit proposals were designed specifically for the case study process (see Section 4.2), based on a literature review of operability issues related to heat integration measures [10]. The process 
data for the retrofit proposals were taken from a previous energy targeting study at the refinery [37]. The proposals were discussed with refinery experts in eleven interviews (see Section 4.3). The results were then summarized and presented to the refinery experts again for confirmation and further discussion at a validation seminar.



Figure 3. The work flow for the interview study.

\subsection{Inventory of Possible Process Operability Implications Related to Heat Integration Measures}

Implementation of new heat recovery measures involves many changes to the process equipment and operation, ranging from new and modified heat exchanger units to changes in pressures, steam balances and interactions between different parts of the process. In this paper, we refer to these changes as "process implications".

In order to discuss different aspects of operability during the interviews, a number of heat integration retrofit proposals were designed that cover different process implications related to operability. To ensure an exhaustive coverage of process implications and operability aspects, a list of potential process implications was compiled based on literature examples and experience from previous process integration projects. The implications included on the list were matched with the operability aspects that were most likely to be affected (see Table 1). After the first round of interviews with plant staff, the list of possible implications was extended if new process implications were identified. Table 1 was also used to design the list of questions to be addressed during the interviews, as described in Section 4.3. 
Table 1. The assumed relations between the process implications of heat integration retrofit measures and the most affected operability factors and practical implementation issues (Marton et al. 2016).

\begin{tabular}{|c|c|c|c|c|c|}
\hline $\begin{array}{l}\text { Implications of Heat Integration } \\
\text { Retrofit Measures }\end{array}$ & Flexibility & Controllability & $\begin{array}{l}\text { Startup/ } \\
\text { Shutdown }\end{array}$ & $\begin{array}{l}\text { Reliability/ } \\
\text { Availability }\end{array}$ & Practical Considerations \\
\hline 1. De-bottlenecking & $x$ & & & & \\
\hline 2. Stream splitting & & $x$ & & & \\
\hline 3. HEN complexity & $X$ & $X$ & & & \\
\hline 4. Reduced load on a furnace & $x$ & $x$ & & & \\
\hline 5. Reduced load on an air cooler & $x$ & $X$ & & & \\
\hline 6. Increased pressure drop in heat exchangers & $x$ & $x$ & & & \\
\hline 7. Change in steam balance & $X$ & $X$ & & & \\
\hline 8. Shut down of furnace before reactor & $x$ & $x$ & $x$ & & \\
\hline 9. Heat exchange between process units & $\mathrm{X}$ & $\mathrm{X}$ & $x$ & & \\
\hline 10. New equipment installation & & & & $x$ & $x$ \\
\hline 11. Rebuilding existing equipment & & & & $x$ & $x$ \\
\hline 12. Pressure differences between streams or high pressures & & & & $x$ & $X$ \\
\hline
\end{tabular}




\subsection{Design of Retrofit Proposals}

Nine HEN retrofit proposals were designed for discussion during the interviews. The proposals were designed to include specific process implications connected to operability and technical implementation aspects. The proposed HEN retrofits were designed within selected process units at the refinery, using a pinch technology approach [41] based on stream data representing normal operating conditions and information about the current placement of heat exchangers.

Previous studies at the refinery, also based on pinch analysis, showed that five process units account for $90 \%$ of the current hot utility use and also have the greatest potentials for utility savings [38]. One of these units has been rebuilt since the data was collected and pinch analysis targeting was conducted. Therefore, the remaining four units were chosen for this study. To be able to investigate operability aspects of heat integration between process units, two units located close to each other were grouped together. Current hot utility usage and theoretical minimum heat demand for the chosen units are listed in Table 2. The analysis and design were conducted for a single operating point which represents normal refinery operation. It should be noted, however, that process operation and ambient conditions vary over time. Although the study includes a single operating point, flexible operation for other process conditions was discussed in the interviews.

Table 2. Current and minimum heat demands for process units included in this paper. For the pinch analysis, the following minimum temperature differences contributions were considered; $\Delta \mathrm{T}_{\min } / 2=10 \mathrm{~K}$ for condensing/boiling hydrocarbons, $\Delta \mathrm{T}_{\min } / 2=5 \mathrm{~K}$ for water, $\Delta \mathrm{T}_{\min } / 2=2.5 \mathrm{~K}$ for boiling water, and $\Delta \mathrm{T}_{\min } / 2=15 \mathrm{~K}$ for other process streams.

\begin{tabular}{ccc}
\hline Unit & Current Heat Demand (MW) & Min Heat Demand (MW) \\
\hline A + B & 125 & 104 \\
C & 26 & 10 \\
D & 46 & 9 \\
\hline
\end{tabular}

The design of retrofit proposals was based on the list of implications presented in Section 4.1. Each retrofit proposal was designed to investigate the effect of some of the specific implications. The retrofit proposals were also designed so that all implications are covered, which can be seen in Table 3. All retrofit proposals are described in detail in Appendix A.

For Unit $A+B$, the main objective was to include heat exchange between two process units (Implication \#9) in the retrofit proposals (Retrofit proposal 1A-C and 2). All proposals for Unit A + B include reduced load on the same furnace, but with different paths for stream pre-heating. The stream pre-heating configurations differ with respect to complexity, additional heat exchanger area requirements, and heat source (hot process streams or hot flue gases). Another aspect included in Retrofit proposal 1B is the replacement of steam heating in a distillation column reboiler by heating by internal heat exchange within the process units. For Unit $C$, three different ways of increasing the pre-heating before a process furnace were considered. The first retrofit proposal, $4 \mathrm{~A}$, involves heat recovery from other process streams currently cooled with overhead air fans. An excess of low-pressure (LP) steam is available at the refinery during most of the year. In Retrofit proposal 4B, excess LP steam is used for the pre-heating, decreasing the number of process interconnections. Retrofit proposal $4 \mathrm{C}$ also uses LP steam for pre-heating, but the proposal includes a stream split. For unit D, two retrofit proposals were designed. The retrofit proposals for unit $\mathrm{D}$ involve heat savings in two different process furnaces that also result in a reduction in high-pressure steam production. The furnace in Retrofit proposal 5 is placed prior to an exothermic reactor and is suggested to be taken out of operation. Both retrofit proposals in unit $\mathrm{D}$ also include process streams with high pressures and heat exchangers with large pressure differences between the process streams. 
Table 3. Implications included in each retrofit proposal.

\begin{tabular}{|c|c|c|c|c|c|c|c|c|c|}
\hline \multirow[b]{2}{*}{$\begin{array}{l}\text { Implications of } \\
\text { Retrofit Measures }\end{array}$} & \multicolumn{4}{|c|}{ Unit A + B } & \multicolumn{3}{|c|}{ Unit C } & \multicolumn{2}{|c|}{ Unit D } \\
\hline & 1A & 1B & 1C & 2 & $4 \mathrm{~A}$ & $4 B$ & $4 \mathrm{C}$ & 5 & 6 \\
\hline 1. De-bottlenecking & & & & & & & & & \\
\hline 2. Stream splitting & & & & & & & & & \\
\hline 3. HEN complexity & & & & & & & & & \\
\hline 4. Reduced load on a furnace & & & & & & & & & \\
\hline 5. Reduced load on an air cooler & & & & & & & & & \\
\hline $\begin{array}{l}\text { 6. Increased pressure drop in } \\
\text { heat exchangers }\end{array}$ & & & & & & & & & \\
\hline 7. Change in steam balance & & & & & & & & & \\
\hline 8. Shut down of furnace before reactor & & & & & & & & & \\
\hline 9. Heat exchange between process units & & & & & & & & & \\
\hline 10. New equipment installation & & & & & & & & & \\
\hline 11. Rebuilding existing equipment & & & & & & & & & \\
\hline $\begin{array}{l}\text { 12. Pressure differences between } \\
\text { streams or high pressures }\end{array}$ & & & & & & & & & \\
\hline
\end{tabular}

\subsection{Interview Procedure}

All interviews in the study were semi-structured interviews that were conducted face-to-face. This enabled good communication as well as the possibility to discuss printouts of flow charts in detail. In addition, semi-structured interviews enable a good combination of structure as well as flexibility with respect to opportunities for follow-up questions and discussion during the interviews [42]. To our knowledge, this method has not been used before for discussing and investigating technical aspects related to implementation of heat integration retrofit measures. The interviews were conducted with technical staff with significant knowledge about operational and technical aspects of the refinery. Most interviews were about one hour long, but there was no time limit. The interviews were conducted in Swedish and all material was transcribed afterwards.

The interview procedure was the same for all technical staff responsible for the process units included in the study. HEN retrofit proposals were shared in advance to give the interviewees an opportunity to prepare for questions and check anything uncertain about the affected part of the process unit. The same set-up of open questions was used to discuss all retrofit proposals. Firstly, open questions were asked about the interviewee's thoughts about potential consequences of implementing the retrofit proposal. For all issues that were identified, solution suggestions were requested and discussed. Following the open questions, more specific questions were asked about operability aspects considered in the design phase of the retrofit proposal. To conclude, the interviewee was asked to list the top three obstacles and grade the retrofit proposals implementation potential from one (low) to four (high). The interviews with mechanical engineers, control engineers, and the process utility system engineer started with a general discussion about their expertise related to process integration. Retrofit proposals that were discussed were sent beforehand. This allowed the interviewees to collect necessary information about the processes affected by the proposals and less experienced engineers could discuss the proposals with more experienced engineers beforehand. The interviews with mechanical engineers, control engineers, and the process utility system engineer also provided an opportunity to verify anything unclear brought up in the previous interviews with operations and process engineers regarding equipment, utility systems, or control systems. Table 4 lists the content discussed in each interview.

Finally, results from the interviews were summarized and presented at a validation seminar which was attended by several of the interviewed engineers as well as managers responsible for process development. The results and main conclusions from the interviews were presented to the refinery experts involved in the study. The refinery experts confirmed and clarified the results. Consequently, a comprehensive and systematic in-depth coverage of the included topics was achieved. 
Table 4. List of interviewees and content discussed in the interviews.

\begin{tabular}{ccc}
\hline & Refinery Responsibilities & Content Discussed \\
\hline 1 & Operations engineer, Unit A and B & Retrofit proposals 1A-C, 2 \\
2 & Process engineer, Unit A and B & Retrofit proposals 1A-C, 2 \\
3 & Operations engineer, Unit C & Retrofit proposals 4A-C \\
4 & Process engineer, Unit C & Retrofit proposals 4A-C \\
5 & Operations engineer, Unit D & Retrofit proposals 5, 6 \\
6 & Process engineer, Unit D & Retrofit proposals 5, 6 \\
7 & Control engineer & Process control system \\
8 & Control engineer & Retrofit proposals 1A, 4C, 5 \\
9 & Process engineer, energy systems & Control of the steam utility system \\
& & Steam utility system and fuel gas system \\
10 & Mechanical engineer, heat exchangers and air coolers & Retrofit proposal 4A, 6 \\
& & Heat exchangers and air coolers \\
11 & Mechanical engineer, boilers and process heaters & Retrofit proposal 1A, 4A, 5 \\
& & Fired heaters and boilers \\
\end{tabular}

\section{Observations and Insights}

In this section, the main observations and insights from the interviews are presented and discussed. The discussion refers to the retrofit proposals that are presented in Appendix A.

\subsection{Practical Considerations}

In almost all interviews, practical considerations were stated as being important for implementing HEN retrofit proposals. The most commonly discussed practical consideration was spatial restrictions in the plant. Other issues that were stated repeatedly were limitation in time and space for making process modifications during expensive turn-around periods and the high cost of equipment operating at high pressure. Although most retrofit proposals involve practical difficulties, it was generally considered that these issues can usually be solved. However, the proposed solutions to the practical problems lead to higher costs that should be accounted for when designing HEN retrofit proposals. For example, retrofit proposal 1A includes doubling of the surface area of a large existing heat exchanger to achieve higher internal heat recovery. There is limited space available in the affected process unit, which makes doubling of the heat exchanger size difficult. However, if the existing shell-and-tube exchanger were to be replaced with new efficient plate heat exchangers, the increased heat recovery could be achieved in a smaller space than the space currently occupied by the existing heat exchanger. To enable cleaning of the new plate heat exchanger during operation, it would be necessary to have two plate exchangers in parallel, but they would still occupy less space than the original shell-and-tube heat exchanger. This was confirmed by a mechanical engineer during interview 10 as well as during the validation seminar:

"Yes, if they are replaced with plate exchangers that should not be an issue. It would require more piping but that would require less space, so I do not see any issues with that."

\section{Mechanical engineer, heat exchangers and air coolers}

Increased pressure drop caused by increased heat exchanger area was highlighted during several interviews as something that always needs to be taken into consideration. Both new and extended existing heat exchangers will lead to increased pressure drop. Pressure drop was mentioned both during the interviews and the seminar. In particular, several interviewees stated that if the pressure drop is too large for the current pump capacity, new pumps will be necessary, and the total investment cost will probably be too high for the retrofit proposal to be implemented. 


\subsection{Maintenance}

During the interviews, increased maintenance was mentioned as a potential issue, particularly the need for both space and time to clean the heat exchangers. If the heat exchangers are not properly cleaned, pressure drops increase significantly, which can cause issues for operation of downstream process units. Heat exchangers that already experience problems with fouling are likely to be penalized by decreased reliability/availability if enlarged, due to the increased need for maintenance during operation. The decreased reliability/availability for tube-and-shell heat exchangers is caused by the need to lower the feed flowrate to the unit to enable cleaning on both tube and shell side of the heat exchanger. One solution stated by several interviewees for fouling issues is to remove existing shell-and-tube exchangers and replace them with parallel plate exchangers. In a number of interviews, it was stated that a simultaneous investment to improve current operability issues caused by fouling could increase the prospect of investing in an energy saving project. This is the case for the previously discussed retrofit proposal 1A. Combining an expansion of the heat exchanger with a replacement of the existing shell-and-tube heat exchanger would not only decrease utility usage but would also decrease fouling problems. This reasoning was confirmed in several of the interviews as well as at the validation seminar.

\subsection{De-Bottlenecking}

Several retrofit proposals turned out to provide opportunities for removing bottlenecks in the production process. De-bottlenecking increases the flexibility of the process. Retrofit proposals that result in load reduction in process furnaces that currently constitute production bottlenecks were ranked higher than other proposals. These debottlenecking implications were identified by the interviewees even though they were not intentionally included in the retrofit proposals during the design procedure. The possibility to increase production or yield of desirable products was declared as important and recurrently discussed in the interviews. For example, the operations engineer in interview 3 stated that

"Well, I am very interested in this, if we can reduce the energy consumption here ... it will not only be an energy aspect, but I think we can increase the flow through the unit as well"

Operations engineer Unit $C$

Regarding the process furnace, HTR-C, included in retrofit proposals $4 \mathrm{~A}-\mathrm{C}$.

\subsection{Controllability and Flexibility}

The effect on flexibility and controllability from increased interconnections and complexity was mentioned as a potential issue, but often needs further investigation to evaluate its significance. For retrofit proposal 1B (see Appendix A), it is suggested to heat a distillation column reboiler by internal heat exchanging instead of with utility steam. The retrofit proposal contains several new interconnections, both within the process unit (Unit B) and between Unit A and Unit B. It was considered a potential problem that the reboiler would become dependent on other parts of the unit. Whether the increased number of interdependencies would have a significant effect on reboiler operability needs to be further investigated. Similar issues were discussed regarding retrofit proposal 4C (see Appendix A) in which a stream split is included. Stream splits are not used to a great extent in the process units for which the interviewed process and operations engineers are responsible and they therefore had no clear opinion about possible impacts on operability. The control engineer, on the other hand, stated that the stream split is possible but new control valves and measurements are needed, as well as a more thorough analysis of the control structure. However, at the validation seminar it was acknowledged that almost all refineries have several well-functioning stream splits in the crude oil pre-heating unit. Both examples (the integration of the reboiler in $1 \mathrm{~B}$ and the stream split in $4 \mathrm{C}$ ) show that a large increase in interdependencies might cause operability issues, but to know whether this is the case, and how it then can be managed, a more thorough analysis is needed. Issues to be investigated include, for example, modeling and simulation and potentially more advanced control structure design. 
Another important aspect discussed concerning flexibility and controllability is that temperatures in several process units change over time due to the deactivation of reactor catalysts. Because of the changing temperatures during the catalyst cycle, it is important to consider the HEN design for more than one operational point.

Large negative effects on flexibility or controllability caused by heat exchange between process units were not discussed to any great extent during the interviews. Units A + B are almost always operated simultaneously, but a back-up solution for heating/cooling needs to be available when one of the units is not in operation. During the validation seminar, the same aspects were discussed, and it was confirmed that it is possible to heat exchange between two process units without any significant decrease in flexibility or controllability. However, this is only the case for units with similar operation patterns and, as previously stated, if there is a back-up solution available when heat exchange is not possible. Heat exchange between two process units that are not operated according to similar schedules was considered very unlikely to be feasible.

\subsection{Safety Aspects}

Safety aspects were discussed in many interviews, especially regarding retrofit proposal 5 (see Appendix A) which involves taking a process furnace (HTR-D1) out of operation since it is not needed from an energy point of view. Increased internal heat exchange could easily replace the heat provided by the furnace. The process furnace is placed immediately upstream of an exothermic reactor which is very sensitive to inlet temperature. During the interviews it was clearly stated that the retrofit proposal would not create a controllability issue with respect to the stabilizing function of the reactor inlet temperature during normal operation. The temperature control would not be affected since the existing control is located upstream of the furnace. However, it was very clear during the interviews that a safety issue could occur. In all interviews regarding retrofit proposal 5, it was explained that it is necessary to be able to rapidly lower the reactor inlet temperature if a runaway reaction occurs. This is currently achieved by shutting down the furnace. If the furnace is to be taken out of operation, another solution would be necessary to stop potential runaway reactions. Possible solutions were discussed during the interviews, but the safety control for the retrofit proposal needs to be thoroughly investigated if the retrofit proposal is to be implemented.

\subsection{Start-Up and Shutdown}

In the interviews, operability aspects related to start-up and shut-down of the process were mostly discussed concerning heat exchange between different process units and taking furnace HTR-D1 out of operation in retrofit proposal 5 (see Appendix A). Regarding heat exchange between different process units, the interviewees stated that the process units are not usually started up and shut down simultaneously. Consequently, back-up solutions for heating/cooling during start-up/shutdown are required for heat integration designs in which heating is provided from a different process unit during normal operation. Regarding retrofit proposal 5, the process furnace is not needed during normal operation. However, HX-D1 in the proposal is dependent on the hot reactor effluent. To start the reaction, heat needs to be added to the process, making the process furnace necessary during start-up.

\subsection{Non-Energy Benefits}

Other than operability considerations and practical implementation issues, non-energy benefits were stated as important for several of the retrofit proposals during the interviews. Many of the non-energy benefits discussed were not considered in the original design of the retrofit proposals, but pointed out by the refinery experts during the interviews. Examples of non-energy benefits that were discussed are de-bottlenecking, reduced load on overloaded air coolers and improved product quality. If the retrofit proposal included a non-energy benefit, the interviewees claimed that this increased the incentive to implement the measure by simultaneously providing an opportunity to increase production or solve an operational issue. This was very clear during both the interviews and 
the validation seminar. Additionally, the retrofit proposals that included non-energy benefits were ranked higher in the interviews. For example, the process engineer in interview number 6 stated that

"If you only consider fuel savings, if we would implement this to save those $8 \mathrm{MW}$, I would give the retrofit score two. But if you consider that we could achieve a bigger revamp and also consider the effects on the tower it would be a three."

Process Engineer, Unit D

Regarding retrofit proposal 6 (see Appendix A). In the validation seminar, it was confirmed that non-energy benefits are important to consider alongside energy efficiency measures and the refinery experts stated that non-energy benefits have been a major decisive factor for previously implemented energy saving projects. Energy projects without other process gains have usually been discarded when planning refinery turn-arounds.

\section{Discussion}

Many of the insights presented in Section 5 have been highlighted in previous research. However, previous studies have only investigated the related aspects individually and separately and have not presented a comprehensive overview of operability and practical implementation issues. Lundberg et al. [43] identified the positive effects of de-bottlenecking the recovery boiler at a Kraft pulp mill if heat integration measures are implemented simultaneously when rebuilding the plant. Dhole and Buckingham [44] proposed a methodology to simultaneously consider pinch analysis and column targeting (modification of column design to fit thermodynamic profiles obtained from pinch analysis) for a refinery, in order to achieve de-bottlenecking without increasing the existing furnace load. See also Li et al. [45] for a description of combining de-bottlenecking and pinch analysis in oil refining industry. These examples indicate that the importance of de-bottlenecking highlighted in the interview study is applicable for other cases than the selected oil refinery. Similar comparisons can be made for technical difficulties such as controllability or flexibility. Although it has previously been shown that non-energy benefits and technical and practical difficulties will have an impact on decision making process for selecting new projects to implement, the results in this paper present a wider perspective. The results show these aspects together rather than separately which enables a discussion of their relative importance. For example, the results indicate that non-energy benefits can outweigh the negative effects of technical and practical difficulties for heat integration retrofit proposals. Economic considerations are included in traditional pinch analysis based design but were not in focus in the retrofit proposals in this work. In traditional pinch design, the profitability of heat integration rebuilds is assumed to depend primarily on the energy cost savings and the investment cost for new heat exchangers. Operability considerations are likely to affect both the operating and investment costs for heat integration retrofit measures. Traditional pinch analysis is conducted for steady-state operation. In order to achieve good dynamic operability, additional equipment might be required, such as advanced control systems and/or over-capacity or back-up systems for flexible production. Additionally, if flexibility is considered, the heat savings can vary for different operating scenarios which change the expected heat savings, affecting the cash flows and the expected profitability. Non-energy benefits also affect the profitability of the heat integration retrofit proposals by increasing the revenues or decreasing the capital costs.

Practical issues discussed during the interviews indicate that spatial limitations should be considered earlier in the screening of alternative investment options. It is usually only the investment cost for a new heat exchanger or for extension of an existing heat exchanger that is included in the analysis. Since practical issues, especially spatial restrictions, were a major part of the issues discussed during the interviews, this is an important parameter to include in the early energy targeting analysis. One way to take this into account is to include spatial restrictions in the choice of $\Delta \mathrm{T}_{\min }$. The optimal $\Delta \mathrm{T}_{\min }$ value is affected by investment and operating costs as well as operability considerations [30]. 
For retrofit studies where space is limited, spatial restrictions should be reflected by a higher value of $\Delta \mathrm{T}_{\min }$ in the screening phase.

Steam balances were discussed in several of the interviews. At large refineries, and other chemical industrial plants, utility systems are often large and complicated. The fuel balances at the studied refinery vary during the year, and during $25 \%$ of the year the refinery has an excess of fuel gas for the steam boilers and process furnaces. As a consequence, the studied refinery often has an excess of low-pressure steam, which is considered as free. For steam at higher pressure levels it is more difficult to know how the overall steam and fuel balances are affected by changes. Since it is not obvious how changes in steam production and consumption affect the overall steam and fuel balances at the refinery, a steam model for the refinery was developed after the interview study and applied to the retrofits that included the steam system (see [36]).

\section{Conclusions}

This paper presented the results of a comprehensive inventory of potential technical barriers and process operability constraints related to the implementation of heat recovery measures in industrial process plants. Unlike previous studies, which mainly focus on single implementation barriers or operability aspects of heat integration measures, we presented a complete inventory of such technical constraints including aspects related to flexibility, controllability, start-up/shutdown, reliability/availability, and other practical considerations related to the implementation of measures.

We also suggested a mapping of these potential technical issues to certain design characteristics that may appear in HEN retrofit designs. This mapping could be used to identify the issues that are most likely to be of importance when evaluating a certain heat recovery design. As such, it was proposed to support a new approach for investigating operability and implementation constraints in the early-stage screening of candidate heat recovery measures in industrial process plants. The approach is based on qualitative analysis by means of an interview study, in which operability and technical implementation issues related to specific heat recovery projects are identified, characterized and described with respect to their impact on implementation potential.

The results from interviews at a large oil refinery used as a case study indicated that technical and practical constraints in the plant have a major influence on how the potential for implementation of the heat integration retrofits are ranked. The process considerations that were highlighted most often in the interview study were spatial limitations and maintenance requirements. Another conclusion from the interviews is that non-energy benefits of an energy-saving project can be far more important than the energy savings as such and may also outweigh potential technical difficulties. An example of this is when the heat savings create an opportunity to remove a production bottleneck.

Based on the ranked importance of technical constraints and productivity benefits, it can be concluded that it would be valuable to take such process aspects into consideration at an earlier design stage than usual when constructing HEN retrofits for increased heat integration. If operability, non-energy benefits and practical implementation issues were considered in earlier-stage techno-economic assessments and screenings of heat recovery measures, several issues could be avoided, and large process benefits could be achieved. The inclusion of those factors would also lead to a better estimation of techno-economic potentials for heat integration measures and thereby a more accurate screening process for different energy efficiency and climate mitigation options.

Future work including additional case studies is needed to further confirm the impacts of operability and other technical constraints on the feasibility and cost-efficiency of HEN retrofit measures, prior to suggesting ways to include the effect of these at an earlier design stage and better quantify their values. It would also be of great value to study how these aspects have affected the evaluation of previously implemented and rejected heat integration measures.

Author Contributions: Conceptualization, S.M. and E.S.; Data curation, S.M.; Formal analysis, S.M.; Funding acquisition, E.S.; Investigation, S.M.; Methodology, S.M. and E.S.; Project administration, E.S. and S.H.; Resources, S.H.; Supervision, E.S. and S.H.; Validation, E.S. and S.H.; Visualization, S.M.; Writing-original draft, S.M.; 
Writing-review and editing, E.S. and S.H. All authors have read and agreed to the published version of the manuscript.

Funding: This research was funded by Preem AB through Chalmers Energy Area of Advance.

Acknowledgments: A number of participants from Preem are gratefully acknowledged for their time, input data and participation in interviews.

Conflicts of Interest: The authors declare no conflict of interest. The funders had no role in the design of the study; in the collection, analyses, or interpretation of data; in the writing of the manuscript, or in the decision to publish the results.

\section{Appendix A Heat Exchanger Network Retrofit Proposals}

In this appendix all retrofit proposals included in the interview study are presented.

Appendix A.1 Unit A/B

All retrofit proposed for the Units A and B reduce the load on furnace HTR-AB1. For the existing configuration of the included process equipment of Unit A, see Figure A1.

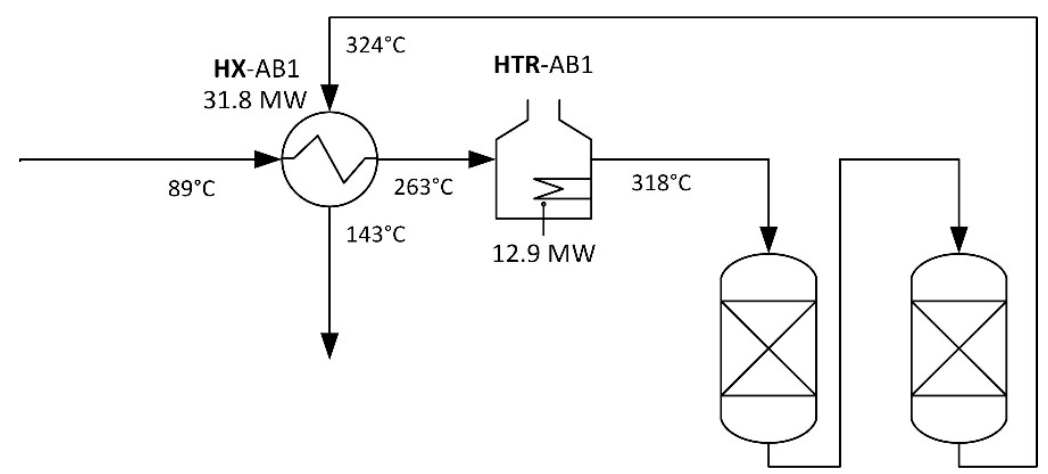

Figure A1. Existing process configuration of effected part of Unit A.

\section{Appendix A.1.1 Retrofit Proposal 1A}

In this retrofit proposal, the feed to furnace HTR-AB1 is pre-heated before entering heat exchanger HX-AB1. The feed is pre-heated by a process stream from Unit $B$, which thereby gets a lower cooling demand, reducing the load on air cooler CLR-AB. Since the heat recovery is very high in this retrofit proposal, the need for new heat exchanger area is large. The retrofit proposal is displayed in Figure A2.



Figure A2. Retrofit proposal 1A. 


\section{Appendix A.1.2 Retrofit Proposal 1B}

Retrofit proposal 1B involves increased heat recovery and network complexity compared to retrofit proposal 1A. The hot stream from Unit B is in this proposal used as a heat source for a distillation column's reboiler, HX-AB3, before preheating the reactor feed in HX-AB2. The proposal is shown in Figure A3.



Figure A3. Retrofit proposal 1B.

Appendix A.1.3 Retrofit Proposal 1C

Retrofit proposal 1C is structurally the same as retrofit proposal 1A. The difference in this proposal is that $\mathrm{HX}-\mathrm{AB} 1$ is not extended, thus changing the temperature of the hot process stream leaving $\mathrm{HX}-\mathrm{AB} 1$ and reducing the fuel saving in the furnace compared to proposal 1A. The proposal is shown in Figure A4.

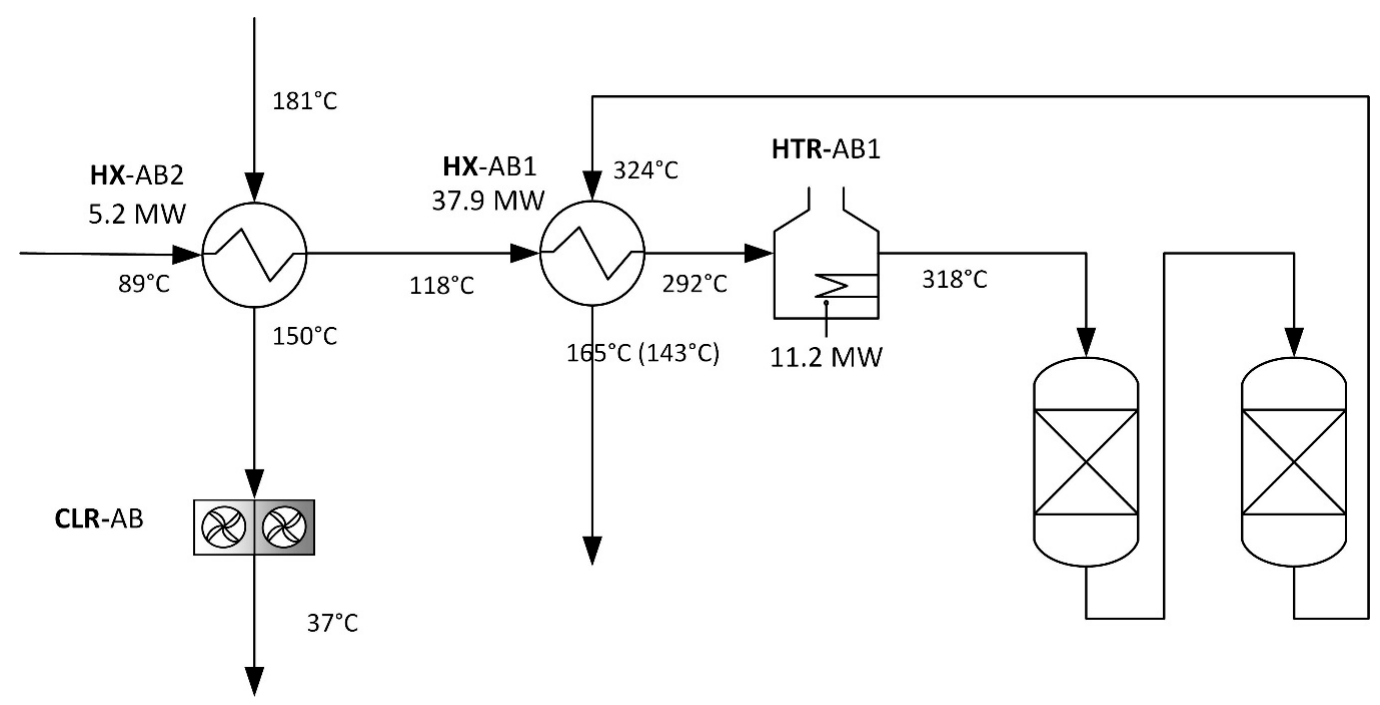

Figure A4. Retrofit proposal 1C. 
Appendix A.1.4 Retrofit Proposal 2

Also in retrofit proposal 2, fuel gas is saved in HTR-AB1. In this case the increased pre-heating is achieved by an additional convection part in HTR-AB2, recovering more energy from the hot flue gases of that furnace. The retrofit proposal is shown in Figure A5.

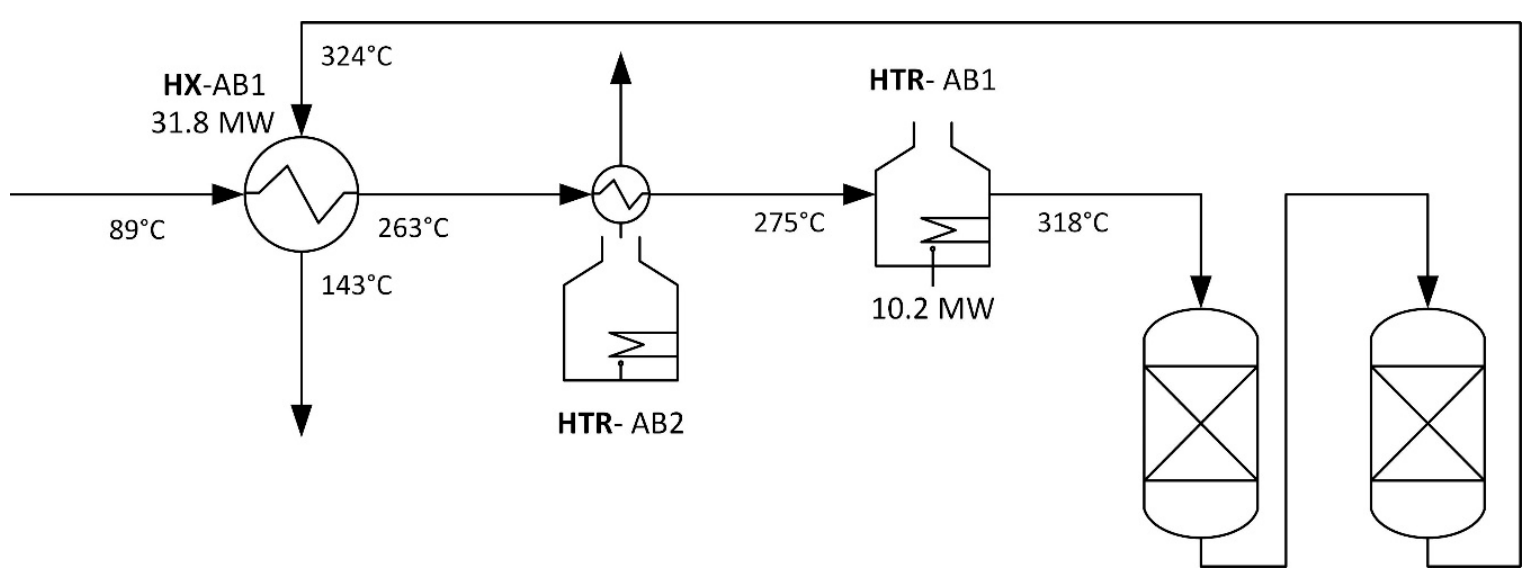

Figure A5. Retrofit proposal 2.

Appendix A.2 Unit C

All retrofit proposals for unit $C$ reduces the load on HTR-C. The current process layout is shown in Figure A6.

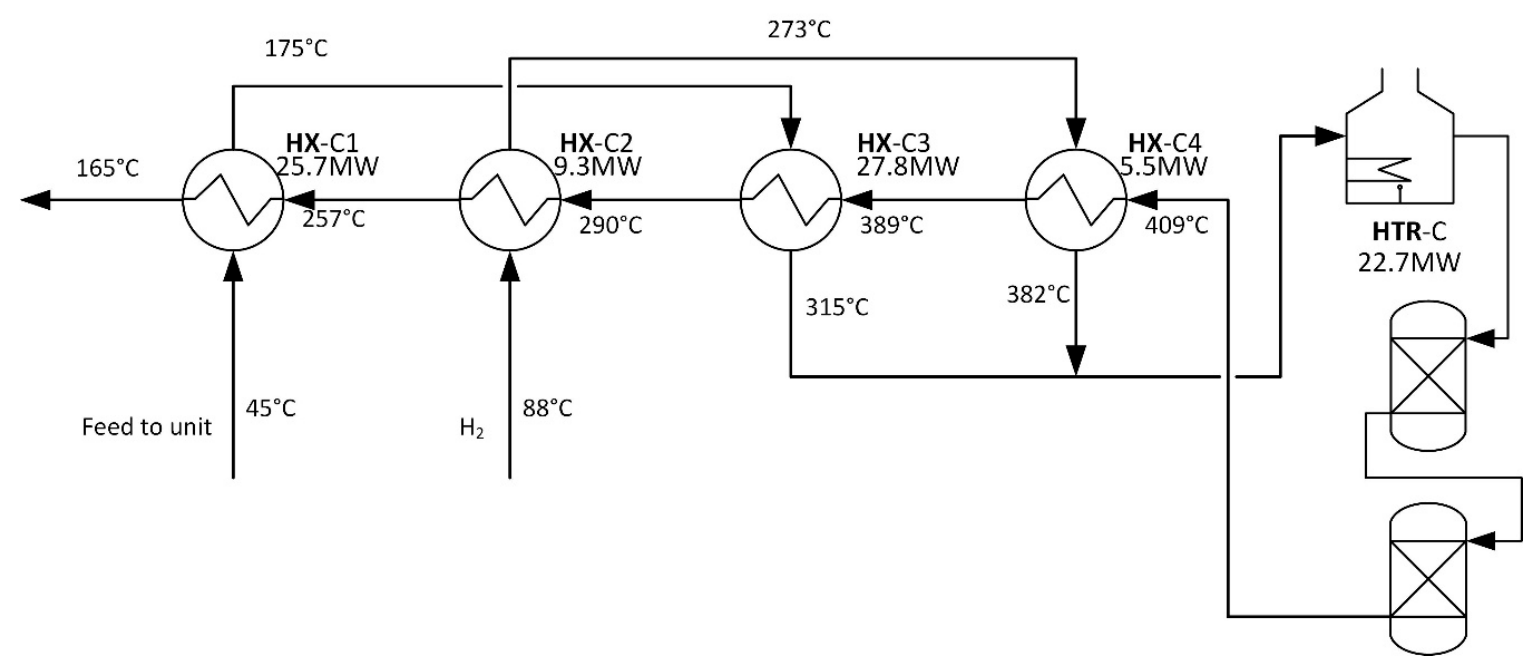

Figure A6. Current process scheme for selected part of Unit C.

Appendix A.2.1 Retrofit Proposal 4A

In retrofit proposal $4 \mathrm{~A}$, the feed is heated by internal heat exchange with other process streams in the same process unit. The pre-heating is smaller than in retrofit proposal $4 \mathrm{~B}$ and $4 \mathrm{C}$, which leads to less fuel savings but also less need for new heat exchanger area. The proposal is shown in Figure A7. 


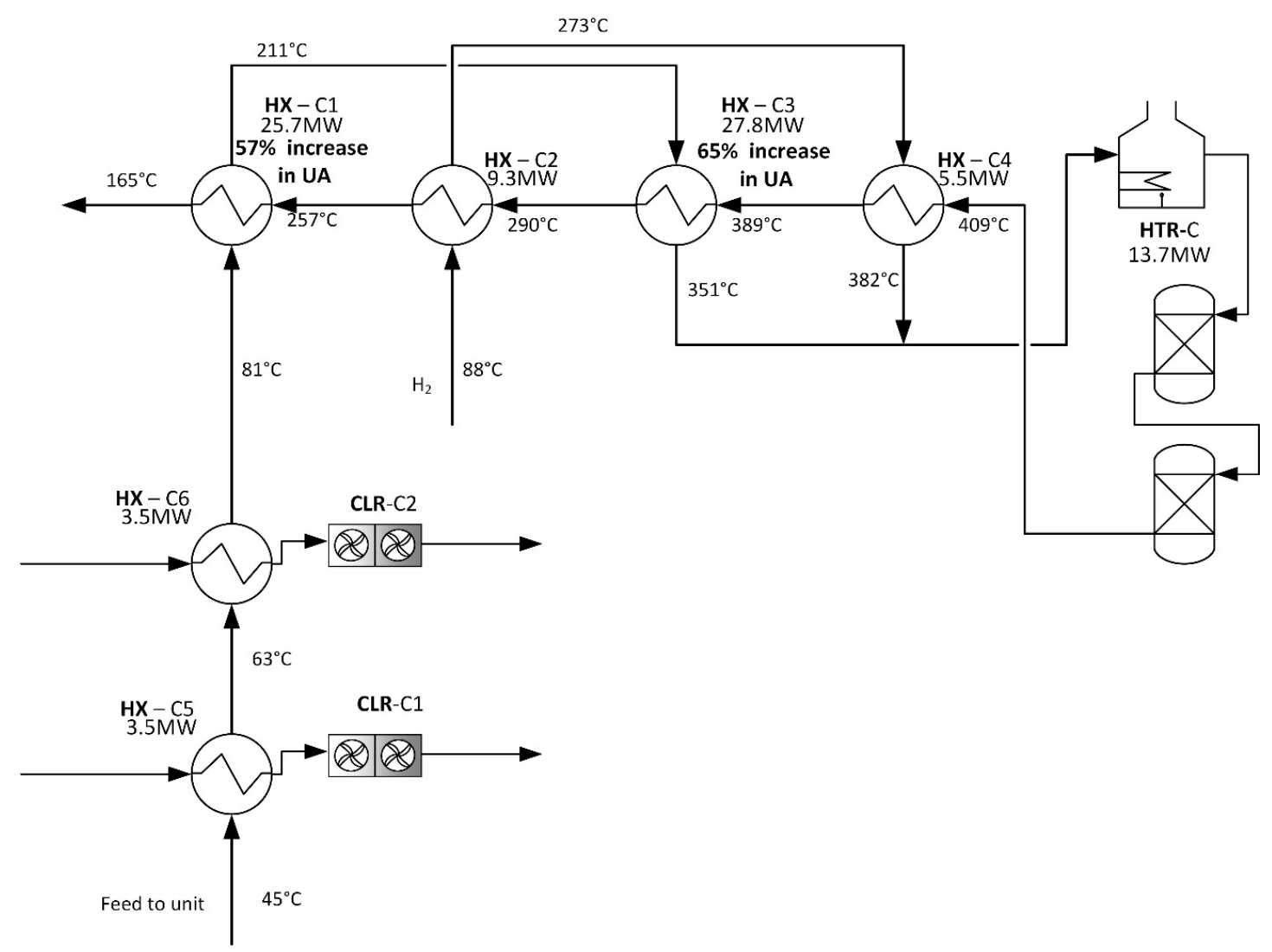

Figure A7. Retrofit proposal 4A.

Appendix A.2.2 Retrofit Proposal 4B

In retrofit proposal 4B, the feed is pre-heated with LP steam. A large part of the year, excess LP steam is vented to the atmosphere. In the proposal, some of this excess LP steam is used. The feed is pre-heated more than in retrofit proposal $4 \mathrm{~A}$, which gives larger fuel savings but bigger area increase in existing heat exchangers. Retrofit proposal $4 \mathrm{~B}$ is shown in Figure A8.

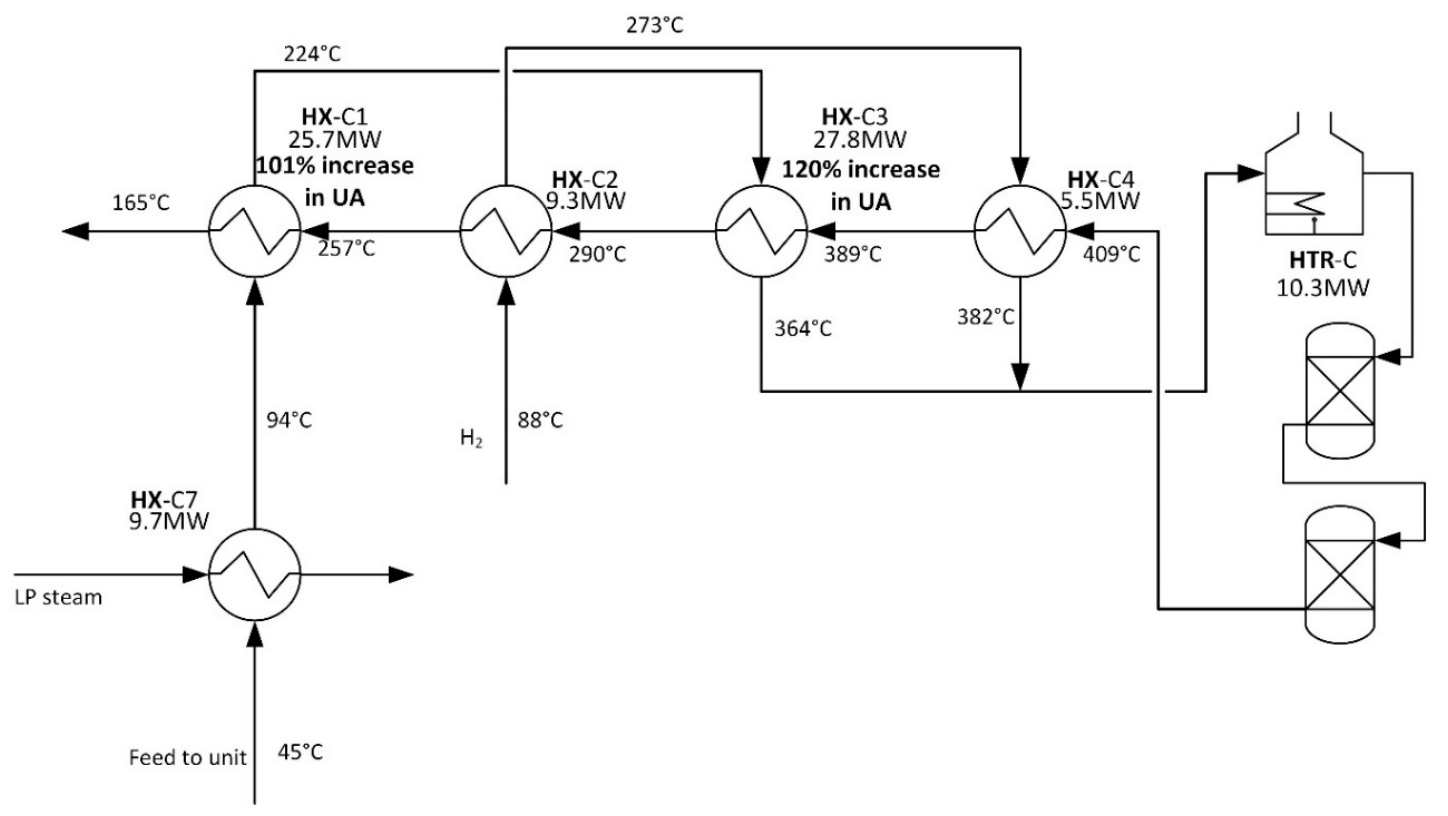

Figure A8. Retrofit proposal 4B. 


\section{Appendix A.2.3 Retrofit Proposal 4C}

In retrofit proposal 4C, the feed is pre-heated with LP steam as in retrofit proposal 4B. The difference is that the piping is changed and the hot reactor effluent is split to two parallel streams. This gives a slightly smaller area increase compared to $4 \mathrm{C}$, but requires more piping and likely a more complex control system. The proposal is shown in Figure A9.

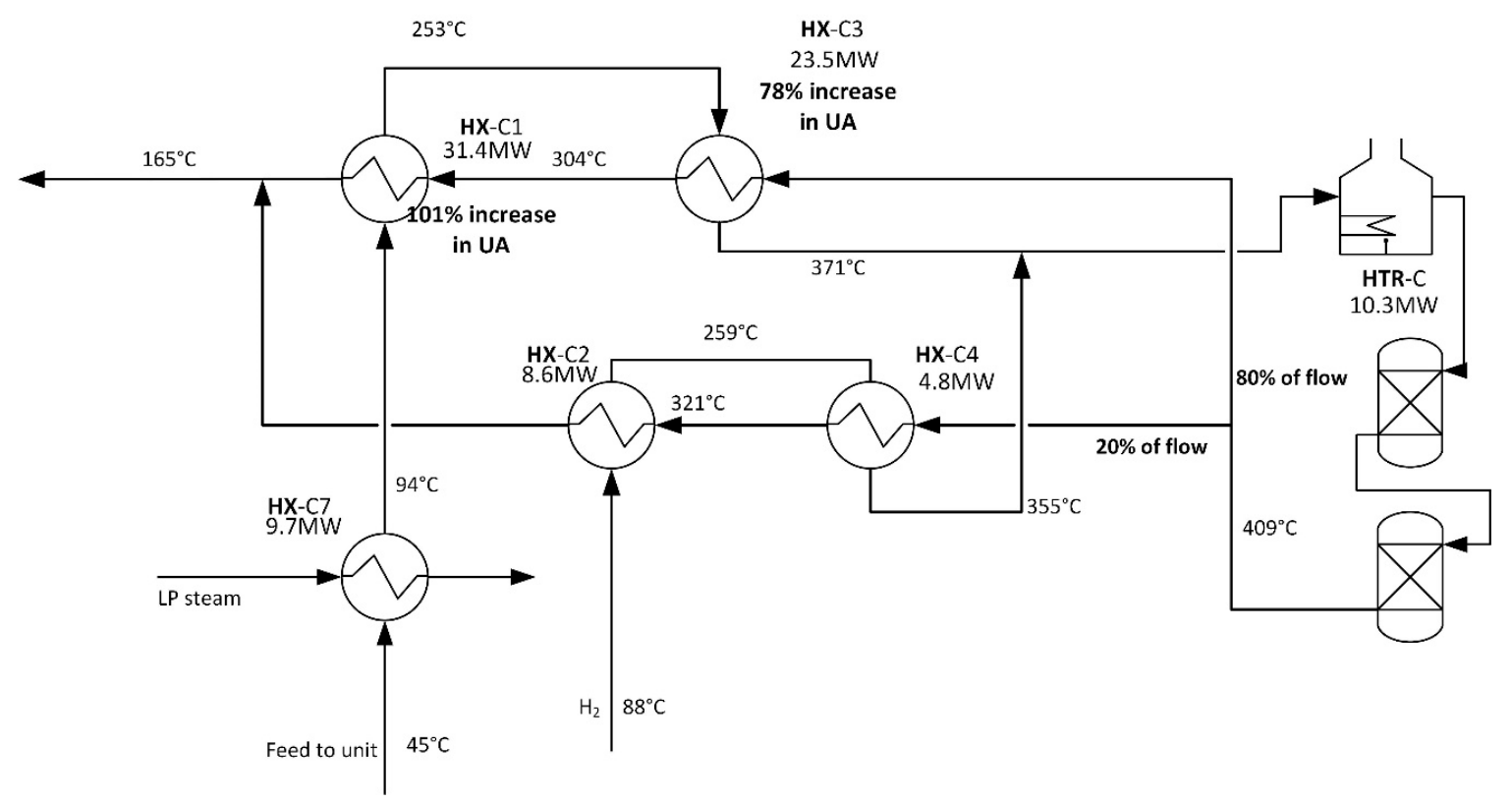

Figure A9. Retrofit proposal 4C.

Appendix A.3 Unit D

For Unit D, two retrofit proposals were designed.

\section{Appendix A.3.1 Retrofit Proposal 5}

In this retrofit proposal, the area in HX-D1 is increased to increase the heat recovery from the hot reactor effluent. When the pre-heating before furnace HTR-D1 is increased, the furnace will not be needed during normal operation. As the hot inlet temperature to SG-D is decreased, the steam generation is also decreased. In addition, the steam generation is further decreased as a consequence of that the pre-heating and superheating that occurs in furnace HTR-D1 is removed if the furnace is shut down during normal operation. The proposal is shown in Figure A10. 



Figure A10. The process current configuration is shown to the left in the figure and retrofit proposal 5 is shown to the right.

\section{Appendix A.3.2 Retrofit Proposal 6}

In retrofit proposal 6, fuel is saved in furnace HTR-D2 by pre-heating the feed by another hot process stream. As in retrofit proposal 5, retrofit proposal 6 leads to lower steam production in steam generator SG-D. The proposal is shown in Figure A11.
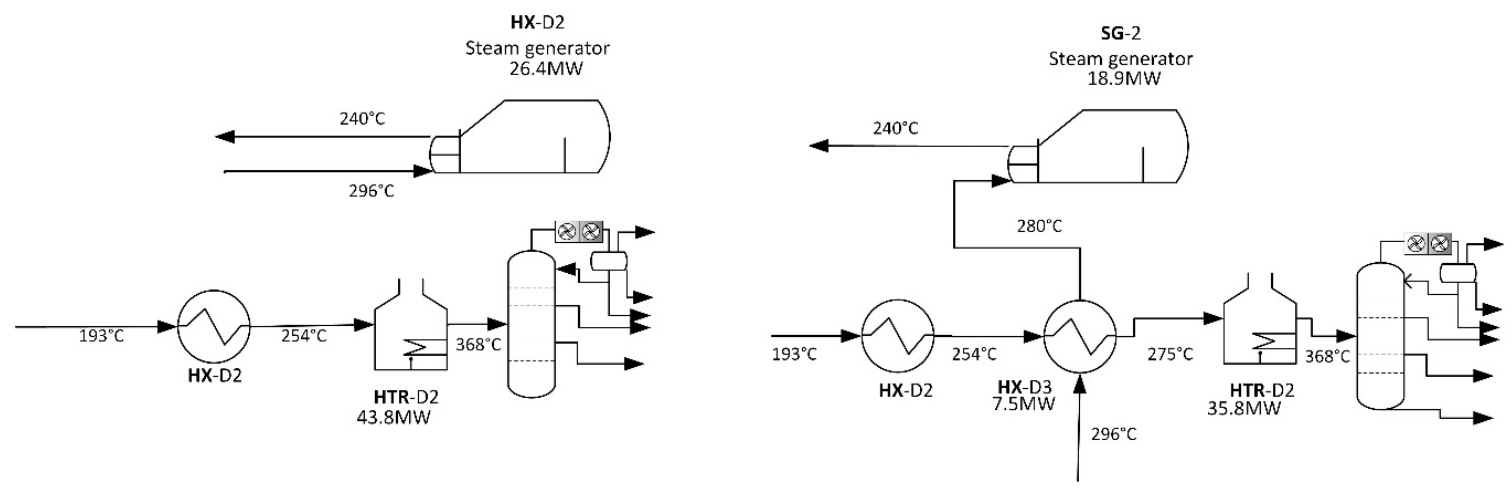

Figure A11. Left part of the figure shows current process configuration and right part of the figure shows the suggested retrofit proposal 6.

\section{References}

1. European Union. Directive 2012/27/EU of the European Parliament and of the Council of 25 October 2012 on Energy Efficiency, Amending Directives 2009/125/EC and 2010/30/EU and Repealing Directives 2004/8/EC and 2006/32/EC Text with EEA Relevance. 2012. Available online: http://eur-lex.europa.eu/eli/dir/2012/27/oj (accessed on 16 April 2019).

2. Fleiter, T.; Hirzel, S.; Worrell, E. The characteristics of energy-efficiency measures-A neglected dimension. Energy Policy 2005, 51, 502-513. [CrossRef]

3. Dieperink, C.; Brand, L.; Vermeulen, W. Diffusion of energy-saving innovations in industry and the built environment: Dutch studies as inputs for a more integrated analytical framework. Energy Policy 2004, 32, 773-784. [CrossRef]

4. Rohdin, P.; Thollander, P.; Solding, P. Barriers to and drivers for energy efficiency in the Swedish foundry industry. Energy Policy 2007, 35, 672-677. [CrossRef] 
5. Thollander, P.; Ottosson, M. An energy efficient Swedish pulp and paper industry—Exploring barriers to and driving forces for cost-effective energy efficiency investments. Energy Effic. 2008, 1, 21-34. [CrossRef]

6. Cagno, E.; Trianni, A. Evaluating the barriers to specific industrial energy efficiency measures: An exploratory study in small and medium-sized enterprises. J. Clean. Prod. 2014, 82, 70-83. [CrossRef]

7. Johansson, M.T.; Thollander, P. A review of barriers to and driving forces for improved energy efficiency in Swedish industry-Recommendations for successful in-house energy management. Renew. Sustain. Energy Rev. 2018, 82, 618-628. [CrossRef]

8. Cagno, E.; Moschetta, D.; Trianni, A. Only non-energy benefits from the adoption of energy efficiency measures? A novel framework. J. Clean. Prod. 2019, 212, 1319-1333. [CrossRef]

9. Brunke, J.C.; Johansson, M.; Thollander, P. Empirical investigation of barriers and drivers to the adoption of energy conservation measures, energy management practices and energy services in the Swedish iron and steel industry. J. Clean. Prod. 2014, 84, 509-525. [CrossRef]

10. Arens, M.; Worrell, E.; Eichhammer, W. Drivers and barriers to the diffusion of energy-efficient technologies-a plant-level analysis of the German steel industry. Energy Effic. 2017, 10, 441-457. [CrossRef]

11. Marton, S.; Svensson, E.; Harvey, S. Investigating Operability Issues of Heat Integration for Implementation in the Oil Refining Industry. In Proceedings of the ECEEE Industrial Efficiency, Berlin, Germany, 12-14 September 2016.

12. IEA. Capturing the Multiple Benefits of Energy Efficiency; International Energy Agency: Paris, France, 2014.

13. Subramanian, S.; Georgakis, C. Methodology for the steady-state operability analysis of plantwide systems. Ind. Eng. Chem. Res. 2005, 44, 7770-7786. [CrossRef]

14. Setiawan, R.; Bao, J. Operability Analysis of Chemical Process Network based on Dissipativity. In Proceedings of the ASCC: 7th Asian Control Conference, Hong Kong, China, 27-29 August 2009; Volume 1-3, pp. 847-852.

15. Setiawan, R.; Bao, J. Analysis of Interaction Effects on Plantwide Operability. Ind. Eng. Chem. Res. 2011, 50, 8585-8602. [CrossRef]

16. Klemeš, J. Sustainability in the Process Industry: Integration and Optimization; McGraw-Hill Professional: New York, NY, USA, 2011.

17. Sreepathi, B.K.; Rangaiah, G.P. Review of heat exchanger network retrofitting methodologies and their applications. Ind. Eng. Chem. Res. 2014, 53, 11205-11220. [CrossRef]

18. Becker, H.; Maréchal, F. Energy integration of industrial sites with heat exchange restrictions. Comput. Chem. Eng. 2012, 37, 104-118. [CrossRef]

19. Cerda, J.; Westerburg, A.W. Synthesizing heat-exchanger networks having restricted stream stream matches using transportation problem formulations. Chem. Eng. Sci. 1983, 38, 1723-1740. [CrossRef]

20. Polley, G.T.; Kumana, J.D. Practical Process Integration Retrofit: Part 4. Dealing with large projects. In Proceedings of the 2012 AIChE Spring Meeting and 8th Global Congress on Process Safety, Houston, TX, USA, 1-5 April 2012.

21. Bütün, H.; Kantor, I.; Maréchal, F. Incorporating Location Aspects in Process Integration Methodology. Energies 2019, 12, 3338. [CrossRef]

22. Hiete, M.; Ludwig, J.; Schultmann, F. Intercompany Energy Integration Adaptation of Thermal Pinch Analysis and Allocation of Savings. J. Ind. Ecol. 2012, 16, 689-698. [CrossRef]

23. Jegla, Z.; Freisleben, V. Practical Energy Retrofit of Heat Exchanger Network Not Containing Utility Path. Energies 2020, 13, 2711. [CrossRef]

24. Reddy, C.C.S.; Rangaiah, G.; Long, L.W.; Naidu, S.V. Holistic Approach for Retrofit Design of Cooling Water Networks. Ind. Eng. Chem. Res. 2013, 52, 13059-13078. [CrossRef]

25. Hackl, R.; Harvey, S. From heat integration targets toward implementation-A TSA (total site analysis)-based design approach for heat recovery systems in industrial clusters. Energy 2015, 90, 163-172. [CrossRef]

26. Nemet, A.; Klemeš, J.J.; Kravanja, Z. Designing a Total Site for an entire lifetime under fluctuating utility prices. Comput. Chem. Eng. 2015, 72, 159-182. [CrossRef]

27. Escobar, M.; Trierweiler, J.O.; Grossmann, I.E. Simultaneous synthesis of heat exchanger networks with operability considerations: Flexibility and controllability. Comput. Chem. Eng. 2013, 55, 158-180. [CrossRef]

28. Leitold, D.; Vathy-Fogarassy, A.; Abonyi, J. Evaluation of the Complexity, Controllability and Observability of Heat Exchanger Networks Based on Structural Analysis of Network Representations. Energies 2019, 12, 513. [CrossRef] 
29. Andiappan, V.; Ng, D.K.S. Systematic analysis for operability and retrofit of energy systems. In Green Energy and Technology; Springer: Singapore, 2018; pp. 147-166. [CrossRef]

30. Abu Bakar, S.H.; Abd Hamid, M.K.; Alwi, S.R.W.; Manan, Z.A. Selection of minimum temperature difference (Delta T-min) for heat exchanger network synthesis based on trade-off plot. Appl. Energy 2016, 162, 1259-1271. [CrossRef]

31. Maréchal, F.; Kalitventzeff, B. Targeting the integration of multi-period utility systems for site scale process integration. Appl. Therm. Eng. 2003, 23, 1763-1784. [CrossRef]

32. Verheyen, W.; Zhang, N. Design of flexible heat exchanger network for multi-period operation. Chem. Eng. Sci. 2006, 61, 7730-7753.

33. Čuček, L.; Martin, M.; Grossmann, I.E.; Kravanja, Z. Multi-period synthesis of optimally integrated biomass and bioenergy supply network. Comput. Chem. Eng. 2014, 66, 57-70. [CrossRef]

34. Bütün, H.; Kantor, I.; Maréchal, F. An Optimisation Approach for Long-Term Industrial Investment Planning. Energies 2019, 12, 4076. [CrossRef]

35. Naturvårdsverket | Swedish Pollutant Release and Transfer Register. Available online: https://utslappisiffror. naturvardsverket.se (accessed on 31 March 2018).

36. Marton, S.; Svensson, E.; Subiaco, R.; Bengtsson, F.; Harvey, S. A Steam Utility Network Model for the Evaluation of Heat Integration Retrofits-A Case Study of an Oil Refinery. JSDEWES 2017, 4, 560-578. [CrossRef]

37. Andersson, E.; Franck, P.-Å.; Åsblad, A.; Berntsson, T. Pinch Analysis at Preem LYR; Chalmers University of Technology: Gothenburg, Sweden, 2013.

38. Åsblad, A.; Andersson, E.; Eriksson, K.; Franck, P.-Å.; Svensson, E.; Harvey, S. Pinch Analysis at Preem LYR II-Modifications; Chalmers University of Technology: Gothenburg, Sweden, 2014.

39. Sovacool, B.K. Energy studies need social science. Nature 2014, 511, 529-530. [CrossRef]

40. Sovacool, B.K. What are we doing here? Analyzing fifteen years of energy scholarship and proposing a social science research agenda. Energy Res. Soc. Sci. 2014, 1, 1-29. [CrossRef]

41. Kemp, I.C. Pinch Analysis and Process Integration: A User Guide on Process Integration for the Efficient Use of Energy, 2nd ed.; Butterworth-Heinemann: Oxford, UK, 2007.

42. Kvale, S. Doing Interviews; Sage Publications: Thousand Oaks, CA, USA, 2007.

43. Lundberg, V.; Axelsson, E.; Mahmoudkhani, M.; Berntsson, T. Converting a kraft pulp mill into a multi-product biorefinery-Part 1: Energy aspects. Nord. Pulp. Pap. Res. J. 2013, 28, 480-488. [CrossRef]

44. Dhole, V.R.; Buckingham, P.R. Refinery Column Integration for De-bottlenecking and Energy-saving. In Proceedings of the ESCAPE-4, the fourth European Symposium on Computer Aided Process, Dublin, Ireland, 30 July 1994; pp. 309-316.

45. Li, S.Y.; Zhang, H.B.; Meng, S.; Lu, H. Improving Energy Efficiency for Refinery through Bottleneck Elimination. Chem. Eng. Trans. 2015, 45, 1159-1164. 